\title{
Patrimônio educativo e história da educação: a biblioteca pública de Santa Catarina como "lugar de memória"
}

\author{
Educational inheritance and history of education: the public library of Santa Catarina as "memory place"
}

\author{
Carolina Ribeiro Cardoso da Silva \\ Hiassana Scaravelli \\ Universidade do Estado de Santa Catarina - UDESC - Florianópolis - Santa Catarina - Brasil
}

\begin{abstract}
Resumo: A noção de patrimônio pressupõe, entre outras coisas, a preservação e a guarda de bens cujo valor social demanda protegê-los do risco de desaparecimento. Dentre os bens patrimoniais de uma sociedade encontram-se aqueles vinculados à memória da educação, os chamados patrimônios educativos. Este artigo propõe dar visibilidade a documentos dessa natureza salvaguardados no setor de Obras Raras da Biblioteca Pública de Santa Catarina. Analisa, primeiramente, a constituição da biblioteca enquanto "lugar de memória". Em seguida, apresenta o setor de Obras Raras, indicando um conjunto de obras que podem ser tomadas como fontes de pesquisa em história da educação. O texto ainda postula a imprescindibilidade de políticas de preservação e de guarda do patrimônio educativo, destacando seu valor para a preservação da memória escolar catarinense.
\end{abstract}

Palavras-chave: Patrimônio Educativo. Memória. História da Educação.

Abstract: The notion of inheritance presupposes, among other things, the preservation and the well keeping of assets whose social value demands to protect them from the risk of disappearance. Among the assets of the heritage of a society are those linked to the memory of education, the so-called educational inheritance. This article aims to give visibility to such documents safeguarded in the Rare Books section of the Public Library of Santa Catarina. It analyzes firstly the establishment of the library as a "place of memory". It then presents the Rare Works sector, indicating a set of works that can be taken as research sources on the history of education. The text also postulates the indispensability of preservation policies and of the well keeping of educational inheritance, highlighting its value for the preservation of Santa Catarinas school memory.

Keywords: Educational Inheritance. Memory. History of Education. 


\section{Introdução}

A noção de patrimônio pressupõe, entre outras coisas, a preservação e a guarda de bens cujo valor social demanda protegê-los do risco de desaparecimento. Dentre os bens patrimoniais de uma sociedade encontram-se aqueles vinculados à memória e à história da educação, os chamados patrimônios educativos, aos quais pretendemos dar visibilidade neste artigo tomando como referência obras salvaguardadas no setor de Obras Raras da Biblioteca Pública de Santa Catarina (BPSC).

Inicialmente, nos pareceu relevante explicitar o que estamos entendendo por patrimônio e, sobretudo, por patrimônio educativo. Conforme Zita Possamai (2012), a etimologia da palavra patrimônio está ligada à ideia de herança, corresponde ao conjunto de bens de propriedade de uma família, de uma empresa, de uma instituição, etc., e pressupõe cuidados de manutenção e guarda com a finalidade de transmissão às futuras gerações. Apesar da acumulação de objetos materiais (e da transmissão de certas práticas sociais) perpassarem diferentes tempos e espaços, é a partir da modernidade que a ideia de conservação de elementos do passado adquiriu um sentido mais preciso, fazendo surgir 0 termo patrimônio na acepção que é considerado hoje. Para a autora, a necessidade de estabelecer uma mediação entre passado e presente, sobretudo a partir do desaparecimento de formas tradicionais de construção de memória, pode explicar em certa medida as motivações que levam o homem moderno a "valorizar o passado a partir do presente; um presente onipresente obcecado por si mesmo e que não tem outro horizonte de perspectiva em função da crise do regime moderno de historicidade, calcado no futuro" (POSSAMAI, 2012, p. 112).

Como os vestígios do passado não podem ser preservados em sua totalidade, o critério "atribuição de valores" passa a constituir uma importante característica para a construção do conceito de patrimônio histórico, uma vez que a noção está intimamente ligada à seleção e à escolha do que se entende como significativo ou de valor social/cultural/político. Essa seleção feita a partir de um olhar especializado, surge como ação política na composição dos estados nacionais e também como ação pedagógica do Estado, num contexto de construção de identidades nacionais (Possamai, 2012). Se o valor da preservação do patrimônio histórico na sociedade moderna/contemporânea parece estar mais ou menos reconhecido, a representação de patrimônio ainda não está totalmente consagrada e diferentes narrativas disputam a elaboração de representações sobre o termo. Ainda assim:

A representação mais comum é aquela que define patrimônio como um conjunto ou coleções de bens culturais dados a priori, herdados historicamente, e que cabe à sociedade preservar, celebrar e valorizar. O patrimônio tem 0 poder de tornar sensorialmente visível a Nação. (POSSAMAI, 2012, p. 115)

O tombamento é uma das formas mais conhecidas de preservação patrimonial e corresponde ao ato administrativo de preservar determinados bens de modificações e destruição, como acontece com muitos prédios e fachadas de edifícios, considerando seu significado cultural, histórico e arquitetônico. É o caso, por exemplo, do tombamento de prédios escolares considerados "modelares" - como um conjunto de escolas normais e grupos escolares construídos nas primeiras décadas da República cuja arquitetura invoca as grandes realizações do Estado no âmbito da instrução pública. Entretanto, temos assistido uma ampliação significativa na concepção de patrimônio, que vem resultando em ações e políticas de preservação de uma série de bens, tangíveis e intangíveis, abarcando muito mais do que a preservação predial.

O tema do patrimônio tem mobilizado o interesse de inúmeros investigadores em história da educação, especialmente a partir da renovação do campo historiográfico ocorrida nas últimas décadas, e com o alargamento de fontes consideradas "válidas" para a pesquisa e escrita da história. Essa ampliação do repertório de documentos históricos tem potencializado a compreensão dos processos 
educativos tanto na sociedade brasileira quanto em outros contextos. Além disso, é possível perceber que "a preponderância de investigações calcadas na documentação escrita ampliou-se nos últimos anos para a cultura material e também para a cultura visual" (POSSAMAI, 2012, 115).

Apesar de indicarmos nesse artigo uma série de obras/registros escritos, em função da característica do acervo pesquisado (setor de obras raras da BPSC), consideramos válido salientar que a noção de patrimônio educativo da qual partilhamos abarca diferentes documentos. A palavra documento está sendo entendida aqui na esteira do autor Jacques Le Goff, para o qual "documento é uma coisa que fica, que dura [...] é monumento. Resultado do esforço das sociedades históricas para impor ao futuro - voluntária ou involuntariamente - determinada imagem de si próprio" (LE GOFF, 1990, 548). Nesse sentido, o patrimônio educativo envolveria tanto registros escritos, quanto objetos, gestos, imagens, sons ou símbolos que "ficaram", "duraram", se "monumentalizaram", sobreviveram ao tempo e nos falam sobre a história da escola, da profissionalização do magistério, da educação/escolarização da infância, etc.

Ao tratar sobre a temática do patrimônio escolar no contexto brasileiro, Rosa Fátima de Souza (2013) destacou a contribuição de estudos que tomam a cultura escolar como chave de análise na pesquisa em história da educação. Investindo na busca de vestígios de práticas, esses estudos frequentemente direcionam os pesquisadores para a consulta a arquivos escolares, que muitas vezes carecem de organização e se encontram em sofrível estado de conservação.

Amontoados em porões, debaixo de escadas, em salas apertadas, distribuídos ao acaso em armários e caixas, descuidados e sem interesse, documentos, quase sempre administrativos, além de coleções de instrumentos científicos, livros didáticos, móveis antigos, troféus, medalhas, entre outros objetos, sobrevivem a intempéries, goteiras, condições de insalubridade, falta de identificação, organização e armazenamento adequado na maioria das escolas. (SOUZA, 2013, p. 205)
A autora problematiza o termo patrimônio escolar, considerando que "o adjetivo escolar é restritivo e implica a exclusão de processos, práticas e materialidades educativas para além das escolas" (SOUZA, 2013, p. 2011). Apesar de tomarmos como referência neste trabalho documentos cujo foco principal é a escola, optamos por utilizar o termo patrimônio educativo ou patrimônio históricoeducativo para afirmarmos nosso posicionamento frente a importância da preservação e da mobilização de fontes que extrapolem a educação escolarizada. É o caso, por exemplo, de documentos vinculados ao "Abrigo de Menores/Lar de Menores" de Santa Catarina, que permitem pensar na história da educação da infância para além da escolarização da infância.

Postulamos a imprescindibilidade de inserir o tema do patrimônio educativo no debate público acerca da seleção, preservação e disponibilidade de acesso a bens culturais. Selecionar o que deve ser preservado, definir os critérios de representatividade e valor histórico, localizar e organizar documentos e objetos são alguns dos desafios em torno da temática. Soma-se a esses a falta de clareza sobre os locais de guarda desses materiais, uma vez que o destino deles nem sempre está assegurado por políticas públicas, favorecendo o descarte de muitos.

Nos últimos anos, diferentes centros de documentação e museus escolares vêm sendo criados no Brasil e se tornado referência na preservação da memória e na produção de investigações históricas em educação, muitos deles vinculados a universidades ${ }^{1}$. As próprias escolas também se constituem em espaços de guarda de documentos/objetos escolares. Mas, para além desses lugares mais específicos, existem outros que salvaguardam memórias da educação escolar, como é o caso de arquivos e bibliotecas públicas. No caso dos arquivos, há uma predominância de documentos de cunho legislativo, estaduais e/ou nacionais, muitos deles preservados por força de lei. As bibliotecas, por sua vez, destinam-se a reunir, preservar e disponibilizar para consulta livros e periódicos (como

\footnotetext{
${ }^{1}$ Sobre isso ver: SOUZA, 2013.
} 
jornais e revistas), tanto de natureza local quanto nacional e internacional. Assim como os centros de documentação e museus escolares, esses espaços (arquivos e bibliotecas públicas) também guardam uma série de materiais considerados patrimônio educativo, como é o caso de livros didáticos, manuais utilizados da formação de professores, relatórios escolares, legislação de ensino, entre outros, que possibilitam múltiplas leituras sobre o lugar social da(s) escola(s).

Nesse artigo, buscamos dar visibilidade a obras afetas à história da educação catarinense que se encontram salvaguardadas no setor de Obras Raras da BPSC. No que diz respeito à sua organização, o texto foi dividido da seguinte forma: primeiramente, apresentamos a biblioteca e sua constituição como "lugar de memória"; em seguida, caracterizamos o setor de Obras Raras de Santa Catarina, indicando um conjunto de obras que podem ser tomadas como fontes para pesquisas em história da educação. Desta forma, pretendemos contribuir com os debates em torno da temática, reforçando a imprescindibilidade de políticas de preservação e de guarda do patrimônio educativo.

\section{A Biblioteca Pública (de Santa Catarina) como "lugar de memória"}

Falar em biblioteca implica pensar na necessidade humana de registrar (que reverberou no advento da escrita) e no desejo de preservar a produção do conhecimento. No que diz respeito à definição do termo, César do Canto Machado (2007) destaca:

Em análise de cunho etimológico, estudiosos da área têm-no como de raiz grega, ou seja, originário de biblion 'livro' + teke 'caixa, depósito'. Anote-se que, a exemplo da maioria das palavras do idioma de Camões, transladou-se do grego para o latim: bibliotheca, que veio a vocabularizar-se, na grafia portuguesa hoje vigorante, com a supressão do h. Disso se conclui, por força de tradução literal, ser uma biblioteca nada mais que depósito de livros ou caixa de livros. (MACHADO, 2007, p. 17 - grifo do original).
Entretanto, para o autor, as expressões "depósito de livros" ou "caixa de livros" são pouco representativas do sentido que a biblioteca (enquanto instituição) efetivamente assume. Partilhamos dessa ideia e entendemos que a função social desse estabelecimento extrapola 0 sentido dessas expressões. A exemplo de outras bibliotecas públicas, a BPSC não constitui um mero depósito de materiais ou acúmulo de documentos, sejam eles livros, jornais, revistas, etc. Trata-se de um lugar de acesso à informação, um espaço de sociabilidades ${ }^{2}$, de práticas culturais $^{3}$ (como as de leitura, por exemplo), um lugar de memória (especialmente se considerarmos o setor de obras raras).

Tomamos a expressão "lugar de memória" na perspectiva apresentada por Pierre Nora (1993), entendendo que esses lugares (museus, arquivos, cemitérios, coleções, bibliotecas, aniversários, etc.), "nascem e vivem do sentimento que não há memória espontânea" e, portanto, é preciso criar lugares que favoreçam uma "vigilância comemorativa". Comemorar assume aqui o sentido de "trazer à memória", de "recordar", de "memorar", pois, sem a instituição desses lugares a história depressa "varreria" os acontecimentos. Para Nora, esses são lugares "onde palpita ainda algo de uma vida simbólica" (NORA, 1993, p. 13).

A memória pode ser entendida aqui como "propriedade de conservar certas informações" (LE GOFF, 1990). A articulação entre biblioteca e memória fica evidenciada na própria missão da BPSC, qual seja, "manter, conservar e desenvolver a memória cultural do estado e promover a divulgação da cultura em geral, incentivando o hábito da leitura" (FUNDAÇÃO CATARINENSE DE CULTURA, 2011 - grifo nosso). Nesse caso, tem-se o desejo de conservar informações em livros, revistas, jornais, etc., uma memória bibliográfica (ESPÍNDOLA; DUARTE, 2014), que sirva de testemunho da história

\footnotetext{
${ }^{2}$ Consideramos a BPSC como espaço de sociabilidades, uma vez que promove exposições artísticas, apresentações musicais, visitas orientadas, "contação" de histórias, etc., favorecendo a interação e o convívio de diferentes grupos sociais.

${ }^{3}$ Sobre isso ver: STEINDEL; TOLEDO, 2013.
} 
de um estado, a fim de evitar uma espécie de "amnésia social" que deponha contra a cultura e a identidade do povo catarinense.

Em Manifesto publicado em 1994, a Unesco (United Nation Educational Scientific and Cultural Organization) registrou seu juízo atinente às missões das bibliotecas públicas, dentre as quais entre destacamos a de "promover a herança cultural" (Unesco, 1994). Na BPSC, uma série de obras produzidas por autores catarinenses e/ou que tiveram relativa circulação no estado (algumas com circulação nacional/internacional) são salvaguardadas por força de lei, como herança (patrimônio) para as gerações futuras. Nesse sentido, ao receber, conservar, salvaguardar e disponibilizar ao público uma série de obras de valor patrimonial, a BPSC cumpre uma de suas funções. Tendo destacado o entendimento de biblioteca como lugar de memória, passamos a apresentar um breve histórico da BPSC.

Fundada em 1854 pelo então presidente da Província de Santa Catarina, João José Coutinho (Presidente Coutinho), e oficialmente inaugurada em 1855, a BPSC é considerada uma das bibliotecas mais antigas do Brasil $^{4}$, sendo mais antiga, inclusive, que a Biblioteca Pública do Estado do Rio de Janeiro e que a biblioteca do Museu Nacional, ambas datadas de 1863, quando o Estado carioca era sede da Corte (MACHADO, 2007). É preciso considerar que antes da efetiva concretização da Biblioteca como órgão oficial do governo catarinense tem-se notícia da efêmera instalação de um Gabinete de Leitura em 1831, quando a província era governada por Feliciano Nunes Pires. Para Machado (2007), o objetivo inicial deste órgão, segundo desejo expresso pelos círculos intelectuais locais, era "agremiar tão-somente os estudiosos da cidade, os quais, em conjunto, nas horas vagas, discutiriam o conteúdo do que de melhor pudesse haver nas editoras e livrarias do Brasil e do mundo" (MACHADO, 2007, p. 27). O autor destaca ainda que, no ano de 1836, formalizou-se a criação de um novo organismo desse gênero, agora voltado à

\footnotetext{
4 Segundo Machado (2007), as informações no tocante à data de instalação da primeira biblioteca pública em território nacional são controversas. O autor salienta que, de maneira geral, estudiosos indicam que a história inicial das bibliotecas públicas no Brasil remonta às primeiras décadas do século XIX.
}

difusão da leitura na Província, sob iniciativa de membros da Sociedade Patriótica. Essa nova agremiação cultural teria sido mais ampla que a primeira, propondo a transformação do ex-Gabinete de Leitura numa biblioteca provincial de caráter público e não mais de acesso a um reduzido círculo da sociedade.

O empreendimento teria gerado uma campanha em Desterro (atual Florianópolis) visando angariar livros juntos aos "conhecidos estudiosos de melhor aquisição econômica" a fim de compor o acervo da instituição que se fundava. Conforme Machado (2007), passado algum tempo, houve a dissolução dessa biblioteca. A criação oficial da Biblioteca Pública da Província viria a ocorrer quase duas décadas depois, mediante a Lei n. 573, de 31 de maio de 1854. A referida lei tratava, entre outras coisas, da constituição do acervo, indicando que o volume inicial seria proveniente essencialmente de doações:

Art. $2^{\circ}$ - A Biblioteca de que trata o artigo antecedente será formada dos volumes que à Assembleia ofereceu o cidadão Joaquim Antônio d'Azevedo, da Corte do Rio de Janeiro, dos que por ventura forem oferecidos por outros cidadãos, e dos que houverem de ser comprados com quantias que a Assembleia para esse fim haja de votar ulteriormente. (SANTA CATARINA, 1854 apud MACHADO, 2007, p. 32)

Desde sua fundação como Biblioteca Provincial, a BPSC passou por diversos "espaçossedes" ${ }^{2}$, sempre na região central da cidade de Florianópolis, capital do estado catarinense. Inicialmente ocupou uma sala nos fundos da Assembleia Legislativa Provincial, contando com um volume de pouco mais de duzentas obras, provenientes de doações, conforme já indicado. Em 1857 foi transferida para o edifício do Liceu e no ano seguinte passou a funcionar no andar térreo da Diretoria da Fazenda Provincial, sendo transferida posteriormente para um prédio na Rua do Livramento (atual Trajano). Em 1907 teve nova mudança de sede, ainda na Rua Trajano / esquina com a Rua

\footnotetext{
${ }^{5}$ Sobre os locais onde a biblioteca funcionou, ver: MACHADO, 2007.
} 
Tenente Silveira, sendo transferida dali em 1908 para os fundos do Palácio do Governo, onde permaneceu durante meio século. Em 1960, devido às obras de alargamento do jardim do Palácio (atual Palácio Cruz e Souza), a biblioteca passou a ocupar um velho casarão da Rua Arcipreste Paiva. Em 1979, a instituição dividiu espaço com outros órgãos públicos, como a Secretaria de Turismo, Cultura e Esporte e Conselho Estadual de Cultura de Esportes, e foi acomodada no prédio que havia servido de residência ao ex-governador Nereu Ramos, à Rua Almirante Alvin. Para "encerrar o ato" da "peça ciranda de mudanças" (Machado, 2007), a biblioteca foi finalmente transferida para o local onde se encontra atualmente, construído em meados de 1980 especialmente para este fim, à Rua Tenente Silveira, no 373 , e está sob responsabilidade da Fundação Catarinense de Cultura (FCC).

Figura 01: Fachada da atual sede da BPSC na Rua Tenente Silveira

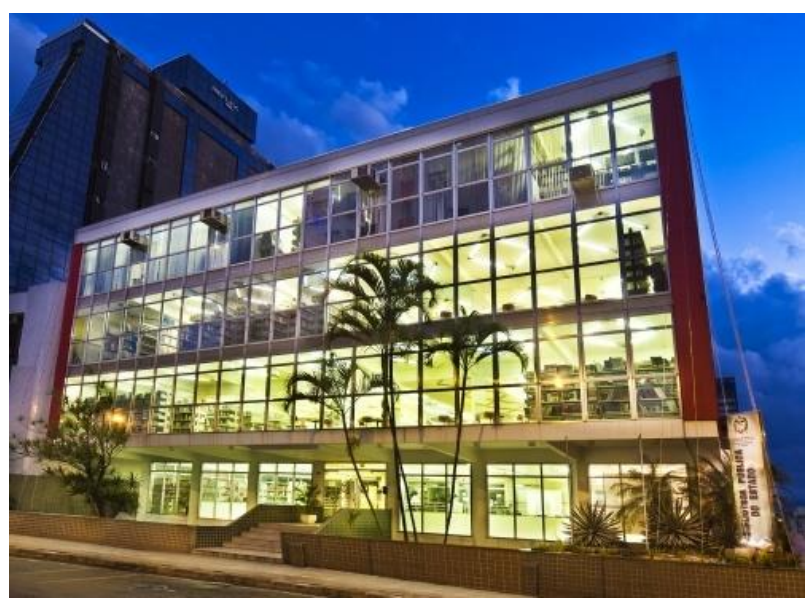

Fonte: Catálogo de Jornais Catarinenses da BPSC (1831-2013), disponível no site da instituição.

Como foi possível perceber, a biblioteca passou por diferentes sedes até a construção de um lugar próprio, o que provavelmente ocasionou a perda de muitas obras. Consideramos válido fazer esse destaque, na medida em que evidencia a importância de políticas públicas que garantam espaços próprios e adequados para a guarda de documentação pública, especialmente aquelas de caráter patrimonial. Pela falta de garantia de um espaço próprio, muitos centros de documentação, arquivos e bibliotecas acabam sendo transferidos de um lugar para outro, sendo por vezes deslocados para localidades de difícil acesso, com instalações impróprias, comprometendo a preservação de bens culturais e a democratização da informação.

$\mathrm{O}$ acervo da BPSC conta com obras adquiridas por compra ou por doações feitas pela comunidade (a exemplo do que acontecia desde sua fundação). Além disso, parte dele é adquirido por meio da Lei $n^{\circ}$ 11.074, de 11 de junho de 1999, que institui o Depósito Legal de Obras Impressas à Biblioteca Pública de Santa Catarina. Por meio desta lei, os administradores de gráficas, editoras, empresas jornalísticas e escritores catarinenses de modo geral têm o compromisso de doarem 1 (um) exemplar de cada obra impressa para o acervo da BPSC, com o objetivo de "assegurar o registro e preservar através da guarda de publicações, a memória do Estado de Santa Catarina" (SANTA CATARINA, 1999). Ainda assim, Espíndola \& Duarte (2014) afirmam que a lei não é totalmente cumprida "por falta de regulamentação oficial" e/ou, acrescentaríamos, por desconhecimento da lei por parte das editoras/escritores ou de um efetivo controle por parte do Estado.

Atualmente, o acervo da BPSC é composto por mais de 115.000 volumes $^{6}$, de diferentes assuntos, e está dividido nos seguintes setores: Literatura, Obras gerais, Periódicos, Braille, Divisão Infantojuvenil, Obras Raras (Gerais e de Santa Catarina). É sobre esse último setor que nos ocuparemos a partir de agora.

\section{Setor de Obras Raras: fontes para a pesquisa em história da educação}

A preocupação em instaurar uma seção "memorial" na biblioteca aparece destacada desde seu primeiro regimento, editado em 1894, na gestão de Hercílio Pedro da Luz à frente do Executivo estadual:

\footnotetext{
6 Informação disponível em: <http://www.biblioteca.sc.gov.br/>. Acesso em: set. 2015.
} 
Art. $4^{0}$ - A Biblioteca terá uma seção destinada ao arquivo de todos os documentos relativos a conhecimentos memoriais, presentes e passados, quer se refiram a fatos sociais, quer a atos simplesmente administrativos, uma vez que sirvam para a história do estado. (SANTA CATARINA, 1894)

A salvaguarda de obras que "sirvam para a história do estado" permanece como uma das funções da BPSC, especialmente do setor de Obras Raras, que tem por finalidade "organizar e conservar de maneira apropriada os materiais raros, antigos e acervos notórios" (FUNDAÇÃO CATARINENSE DE CULTURA, [20--?]). O setor abriga documentos dos séculos XVII, XVIII, XIX e XX (até aproximadamente a década de 1960) e possui mais de 8.700 (oito mil e setecentos) exemplares inventariados. A divisão é feita de acordo com a origem das obras e organizada em duas coleções: Obras Raras Gerais ${ }^{7}$ (internacionais e nacionais) e Obras Raras de Santa Catarina, sendo os critérios para definição de "raridade" baseados naqueles disponibilizados pela Biblioteca Nacional ${ }^{8}$ e pelo Plano Nacional de Recuperação de Obras Raras $^{9}$ (ESPÍNDOLA; DUARTE, 2014).

O setor está localizado no $3^{\circ}$ andar da biblioteca. O contato com os materiais não é de livre manuseio do público, sendo a retirada das estantes feita somente pelos funcionários. Como se pode inferir, as obras são de consulta local, não sendo

\footnotetext{
7 Apesar de não mobilizarmos as Obras Raras Gerais, consideramos importante destacar aqui algumas de suas coleções, como: Coleção Biblioteca das Moças; Coleção Civilização Brasileira; Coleção História das Américas; Coleção Brasiliana e Coleção Obras Completas de Rui Barbosa.

8 De acordo com informações presentes no site da Biblioteca Nacional, os dois critérios principais de seleção de exemplares a compor o setor de Obras Raras são: raridade e preciosidade. Ou seja, "não basta que a obra seja antiga, é preciso também que seja única, inédita, faça parte de alguma edição especial ou apresente algum traço de distinção, como uma encadernação de luxo ou o autógrafo de uma celebridade - como D. Pedro II, Coelho Neto, Carlos Drummond de Andrade ou Jorge Amado" (Biblioteca Nacional). Disponível em: <https://www.bn.br/explore/acervos/obras-raras>.

${ }^{9}$ Critérios de raridade empregados para a qualificação de obras raras do PLANOR: 1) Primeiras impressões (Séc. XV - XVI); 2) impressões dos séculos XVII e XVIII; 3) Brasil - séc. XIX; 4) edições clandestinas; 5) edições de tiragens reduzidas; 6) edições especiais (de luxo para bibliófilos); 7) exemplares de coleções especiais (regra geral com belas encadernações e exlibris); 8) exemplares com anotações manuscritas de importância (incluindo dedicatórias); 9) obras esgotadas (PLANOR). Disponível em: < http://planorweb.bn.br/documentos.html>.
}

permitidos empréstimos domiciliares. Para a reprodução dos materiais é vetado o uso de fotocópias, sendo autorizada apenas a utilização de fotografia digital, sem uso de flash. O manuseio exige cuidados especiais como uso de luvas, a fim de melhor conservar os documentos ${ }^{10}$. Algumas obras, como é o caso dos jornais, são mantidas em ambiente climatizado, com temperatura média entre $21^{\circ} \mathrm{C}$ e $23^{\circ} \mathrm{C}$. Todos esses cuidados evidenciam a natureza "patrimonial" do setor.

Quanto à organização, as obras estão dispostas em estantes e em caixas, como é possível perceber nas figuras abaixo.

Figura 02: Parte do acervo do Setor de Obras Raras
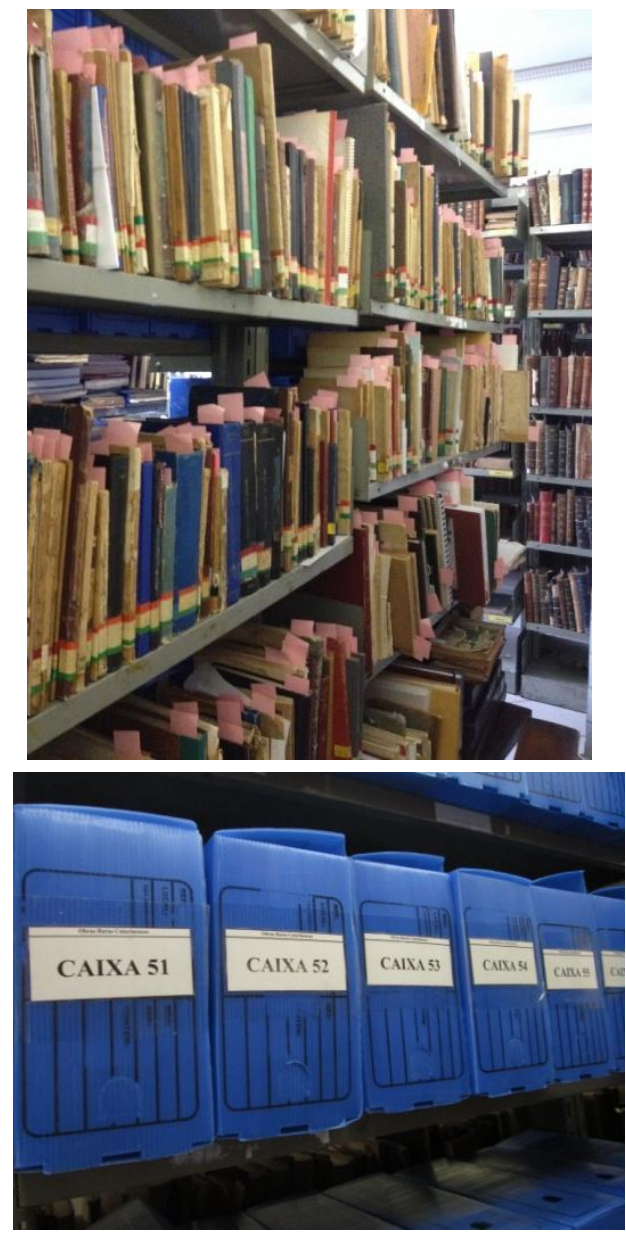

10 A biblioteca conta com um Laboratório de Conservação, Restauração e Encadernação (LACRE), responsável pela conservação e recuperação do acervo danificado pela ação do tempo e pelo uso. Atualmente este laboratório não está em atividade por falta de profissional especializado para o serviço. A retomada e manutenção do LACRE é de fundamental importância, tendo em vista o cuidado especializado que as obras demandam. 
Fonte: Biblioteca Pública de Santa Catarina - Setor de Obras Raras. Imagem: Acervo pessoal das autoras.

Entre as principais tipologias documentais estão livros, revistas, jornais e legislação, com assuntos de naturezas diversas. Devido ao expressivo volume de obras, consideraremos, para este artigo, apenas a coleção Obras Raras de Santa Catarina (ORSC), com 3.005 (três mil e cinco) exemplares registrados (ESPÍNDOLA; DUARTE, 2014). O serviço de inventário da ORSC encontra-se em fase de construção e tem sido realizado aos poucos pelos funcionários do setor, em virtude das outras demandas da biblioteca, como o atendimento ao público.

Para a realização deste trabalho, tomamos como referência o catálogo que nos foi cedido pelo bibliotecário responsável pelo setor ${ }^{11}$, datado de 2012. Com cerca de 120 (cento e vinte) páginas, o documento não apresenta divisões específicas por século/assunto. Selecionamos as obras que nos pareceram mais afetas à educação com base nos títulos e não numa análise mais aprofundada dos conteúdos, portanto, é possível que haja exemplares relacionados à educação catarinense que não tenham sido por nós contemplados. Não seria possível apresentar aqui todos os materiais da coleção ORSC que se relacionam diretamente ao ensino; selecionamos aqueles que consideramos mais representativos, ainda que tenhamos em mente que toda a seleção é, por si só, arbitrária.

A fim de apresentar ao leitor uma amostra dos documentos disponíveis na coleção ORSC, organizamos esta seção em quatro partes, seguindo a lógica de agrupamento por nós realizada: legislação do ensino, livros e revistas, obras diversas, jornais (hemeroteca). Como não seria possível comentar todas as obras, apresentamos uma imagem característica de cada grupo, tecendo breves comentários sobre estas. Os demais títulos e anos das obras poderão ser visualizados nos quadros que elaboramos com o intuito de facilitar a identificação

11 Registramos aqui nosso agradecimento ao bibliotecário Evandro Jair Duarte. dos materiais, aqui tomados como patrimônio educativo catarinense.

Legislação do ensino

Figura 03: Capa do Decreto n. 3786 de janeiro de 1947

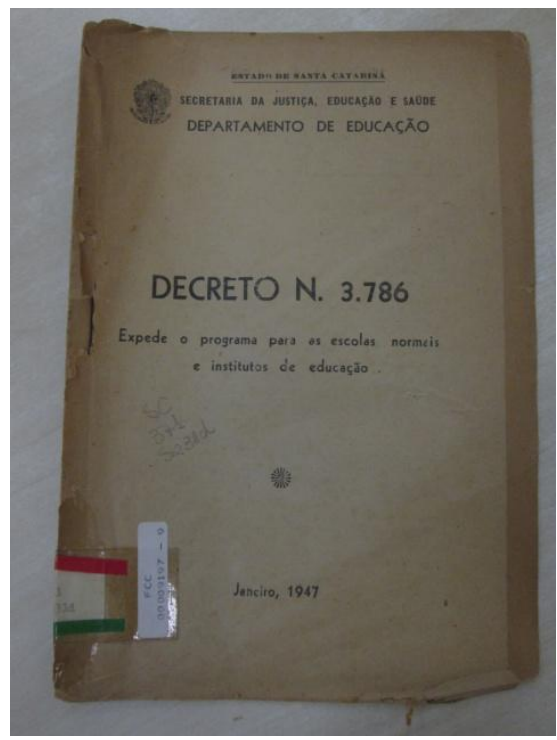

Fonte: Biblioteca Pública de Santa Catarina - Coleção Obras Raras de Santa Catarina. Imagem: Acervo pessoal das autoras.

Apesar do crescente alargamento das fontes mobilizadas pelos historiadores da educação, especialmente nos últimos anos, os documentos normativos/legislativos continuam sendo utilizados como base empírica em muitas pesquisas. Ao publicar o resultado de um balanço sobre as produções feitas na área, Diana Vidal e Luciano Faria Filho (2005) apontaram a continuidade de utilização de fontes tradicionalmente manipuladas pelos historiadores da educação, tais como a legislação e os relatórios oficiais. Isso porque esse tipo de documento tem "algo a dizer" do passado e da circunstância na qual foi produzido, que, pelo entrecruzamento com outras fontes, auxilia a desnaturalizar determinadas práticas educativas. A leitura histórica a partir desses documentos possibilita analisar a voz do Estado representada nas políticas educacionais e a favorece a reflexão sobre a relação entre história política e história escolar/da educação. 
A figura 03 apresenta a capa de um documento dessa natureza. Trata-se do Decreto 3.786, de 28 de janeiro de 1947, que expede o Programa para as Escolas Normais e Institutos de Educação de Santa Catarina, para cumprimento do decreto-lei n. 257 de 21 de outubro de 1946 (Lei Orgânica do ensino normal no estado). As escolas normais e institutos de educação eram destinadas à a formação do professorado catarinense, portanto, ao analisar o referido Decreto, é possível identificar as disciplinas/cadeiras que deveriam compor a formação dos professores naquele período. São elas: português, matemática, física, química, sociologia geral, sociologia educacional, história e filosofia da educação, psicologia educacional, metodologia geral, metodologia do ensino primário, anatomia e fisiologia humanas, higiene e educação sanitária, higiene e puericultura, biologia educacional, desenho e artes aplicadas, trabalhos manuais, música e canto, educação física, recreação e jogos. Fica evidente, nesse tipo de documento, os saberes considerados indispensáveis ao professor, bem como a normatização do estado no que diz respeito à formação do magistério. O quadro 1 permite visualizar outros documentos dessa natureza que compõe a coleção ORSC.

\section{Quadro 1: Legislação do Ensino}

\begin{tabular}{|l|c|}
\hline \multicolumn{1}{|c|}{ TÍTULO DATA } & D \\
\hline $\begin{array}{l}\text { Decreto lei n० 301 - normas para } \\
\text { obrigatoriedade do ensino primário, institue } \\
\text { a quitação escolar e cria o registro do } \\
\text { censo escolar }\end{array}$ & 1939 \\
\hline $\begin{array}{l}\text { Decreto n. 257 expede a lei orgânica do } \\
\text { ensino normal no Estado de Santa Catarina }\end{array}$ & 1946 \\
\hline $\begin{array}{l}\text { Decreto n. 3674 - expede regulamento } \\
\text { para os estabelecimentos de ensino normal }\end{array}$ & 1946 \\
\hline $\begin{array}{l}\text { Decreto n. 3682 - expede o programa para } \\
\text { os cursos normais regionais }\end{array}$ & 1946 \\
\hline $\begin{array}{l}\text { Decreto n. 3732 - expede o programa para } \\
\text { os estabelecimentos de ensino primário do } \\
\text { Estado de Santa Catarina }\end{array}$ & 1946 \\
\hline
\end{tabular}

\begin{tabular}{|l|c|}
\hline $\begin{array}{l}\text { Decreto n. 3733 - expede regulamento para o } \\
\text { serviço de inspeção escolar }\end{array}$ & 1946 \\
\hline $\begin{array}{l}\text { Decreto n. 3735 - regulamento para os } \\
\text { estabelecimentos de ensino primário no } \\
\text { Estado de Santa Catarina }\end{array}$ & 1946 \\
\hline $\begin{array}{l}\text { Decreto n. 3786 - expede o programa para } \\
\text { as escolas normais e institutos de educação }\end{array}$ & 1947 \\
\hline $\begin{array}{l}\text { Decreto-lei n. 301 - estabelece normas para } \\
\text { a obrigatoriedade do ensino primário, institui } \\
\text { a quitação escolar e cria o registro do censo } \\
\text { escolar }\end{array}$ & 1939 \\
\hline $\begin{array}{l}\text { Decreto-lei n. 88 - estabelece normas } \\
\text { relativas ao ensino primário, em escolas } \\
\text { particulares no Estado }\end{array}$ & 1938 \\
\hline $\begin{array}{l}\text { Lei n. 2975, de 18 de abril de 1961 - dispõe } \\
\text { sobre Educação e Cultura }\end{array}$ & 1961 \\
\hline $\begin{array}{l}\text { Lei n. 5692/11/08/71 e resumo dos projetos } \\
\text { do plano setorial de educação }\end{array}$ & 1972 \\
\hline $\begin{array}{l}\text { Regulamento Geral do Ensino Público e } \\
\text { Programa das Escolas Primárias Municipaes } \\
\text { (Joinville) }\end{array}$ & 1918 \\
\hline Regulamento da instrução pública & 1897, \\
\hline $\begin{array}{l}\text { Regulamento e Regimento interno do } \\
\text { Instrucção da Laguna Lapagesse }\end{array}$ & 1894 \\
\hline Regulamento das caixas escolares & 1908, \\
\hline Regulamento do Instituto Municipal de & 1902 \\
\hline & 1913 \\
\hline
\end{tabular}

Fonte: Inventário do setor de Obras Raras de Santa Catarina (2012). Quadro elaborado pelas autoras.

Como foi possível perceber, a maior parte da legislação refere-se especialmente à segunda metade do século $X X$, sendo poucas as que fazem referência direta à instrução pública no século XIX. Vemos uma predominância de leis relativas ao ensino primário e escola normal. Outras modalidades de ensino, como secundário/ginasial/superior, possivelmente são tratadas em leis mais gerais.

Livros e revistas 
Figura 04: Quatro volumes do Livro de Leitura (Série Fontes)

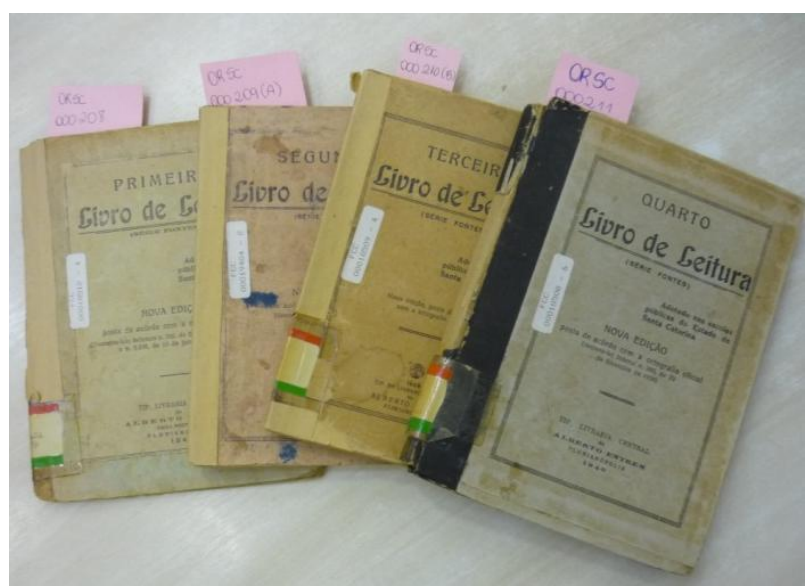

Fonte: Biblioteca Pública de Santa Catarina - Coleção Obras Raras de Santa Catarina. Imagem: Acervo pessoal das autoras.

A figura 04 mostra as capas de quatro volumes do Livro de Leitura da Série Fontes. Trata-se de livros didáticos destinados à escola primária catarinense, utilizados no estado especialmente entre os anos de 1920 e 1950, que reúnem um conjunto de lições, textos, fábulas e poesias de autores locais e nacionais, com temas que enfatizam aspectos como civismo, patriotismo, cultura e tradições (SCHENA, 2014). A chamada "Série Fontes" é fruto do trabalho de Henrique da Silva Fontes, importante intelectual catarinense à época, e permite identificar o processo de produção e apropriação de ideias pedagógicas feito pelo autor.

A exemplo desta, a maioria das obras dessa natureza são relativas à segunda metade do século $\mathrm{XX}$, ainda que encontremos algumas mais antigas. Entre os livros, a maioria são didáticos e voltados para a escola primária. Esse tipo de material serviu/serve como instrumento de trabalho do professor na mediação e transmissão de conhecimentos e sua análise favorece a compreensão acerca das formas de ensinar nas escolas, bem como da relação entre história da educação e história editorial. Dentre as obras listadas no quadro 2, destacamos um título sobre a escola brasileira, escrito em francês, que possivelmente tenha circulado em Santa Catarina, uma vez que compõe a coleção ORSC. O número de revistas é bastante reduzido, mas indicamos alguns títulos por entender que esse tipo de impresso permite identificar discursos pedagógicos que estiveram presentes na formação e atuação de professores catarinenses. Como não há a identificação de autoria no catálogo, consultamos todas as obras listadas no quadro 2 a fim de mostrar ao leitor quem as produziu.

\section{Quadro 2: Livros e Revistas}

\begin{tabular}{|c|c|c|}
\hline TÍTULO & AUTORIA & DATA \\
\hline $\begin{array}{l}\text { Almanaque Sagrado } \\
\text { Coração de Jesus }\end{array}$ & $\begin{array}{l}\text { Colégio } \\
\text { Sagrado } \\
\text { Coração de } \\
\text { Jesus }\end{array}$ & 1941 \\
\hline $\begin{array}{l}\text { A alfabetização no curso } \\
\text { primário e outros estudos }\end{array}$ & $\begin{array}{l}\text { Autor não } \\
\text { identificado }\end{array}$ & 1958 \\
\hline $\begin{array}{l}\text { Cartilha popular: adotado } \\
\text { nas escolas públicas do } \\
\text { Estado de Santa Catarina }\end{array}$ & $\begin{array}{l}\text { Autor não } \\
\text { identificado }\end{array}$ & 1948 \\
\hline $\begin{array}{l}\text { École brésilienne de la } \\
\text { vérite. Nouveau systéme } \\
\text { philoshophique }\end{array}$ & $\begin{array}{c}\text { Gênêral } \\
\text { Liberato } \\
\text { Bittencourt }\end{array}$ & 1936 \\
\hline $\begin{array}{l}\text { Educação physica, } \\
\text { intellectual e moral }\end{array}$ & $\begin{array}{c}\text { Liberato } \\
\text { Bittencourt }\end{array}$ & [s.d] \\
\hline Ensinando a ensinar errado & $\begin{array}{l}\text { Ildefonso } \\
\text { Juvenal }\end{array}$ & 1946 \\
\hline $\begin{array}{l}\text { Estudos Educacionais - } \\
\text { Órgão do Instituto de } \\
\text { Educação de Florianópolis }\end{array}$ & $\begin{array}{l}\text { Fundador: Prof. } \\
\text { J. Roberto } \\
\text { Moreira } \\
\text { Diretor - Prof. } \\
\text { Antonieta de } \\
\text { Barros }\end{array}$ & 1946 \\
\hline $\begin{array}{l}\text { Gramática Alemã - Curso } \\
\text { Progressivo (3ª edição) }\end{array}$ & Padre Fontes & 1934 \\
\hline Licções de Coisas & $\begin{array}{c}\text { Liberato } \\
\text { Bittencourt }\end{array}$ & 1917 \\
\hline
\end{tabular}




\begin{tabular}{|c|c|c|}
\hline Lições de aritmética & $\begin{array}{c}\text { Autor não } \\
\text { identificado }\end{array}$ & 1894 \\
\hline $\begin{array}{l}\text { Lições de geometria } \\
\text { álgebra }-2^{\circ}, 3^{\circ}, 5^{\circ} \text { e } 6^{\circ} \text {. }\end{array}$ & $\begin{array}{l}\text { Autor não } \\
\text { identificado }\end{array}$ & $\mathrm{s} / \mathrm{d}$ \\
\hline Nacionalização e ensino & $\begin{array}{c}\text { Carlos Gomes } \\
\text { de Oliveira }\end{array}$ & 1939 \\
\hline $\begin{array}{ll}\text { Nacionalização } & \text { do } \\
\text { ensino primário } & \end{array}$ & $\begin{array}{c}\text { Orestes } \\
\text { Guimarães }\end{array}$ & 1929 \\
\hline Novas Cartas Jesuíticas & $\begin{array}{l}\text { Serafim Leite } \\
\text { S. I. }\end{array}$ & 1940 \\
\hline $\begin{array}{l}\text { Noções do sistema } \\
\text { métrico decimal }\end{array}$ & $\begin{array}{c}\text { Autor não } \\
\text { identificado }\end{array}$ & 1873 \\
\hline $\begin{array}{l}\text { O Ensino da Geografia } \\
\text { na Escola Secundária }\end{array}$ & $\begin{array}{l}\text { Paulo } \\
\text { Fernando } \\
\text { Lago }\end{array}$ & s.d \\
\hline $\begin{array}{ll}\text { Os jesuítas em Santa } \\
\text { Catarina e o ensino de } \\
\text { humanidades } \\
\text { província }\end{array}$ & $\begin{array}{l}\text { Oswaldo } \\
\text { Rodrigues } \\
\text { Cabral }\end{array}$ & 1940 \\
\hline $\begin{array}{l}\text { Orientação - a revista do } \\
\text { educador (n. } 22 \text { e n. } 31 \text { ) }\end{array}$ & $\begin{array}{c}\text { Autor não } \\
\text { identificado }\end{array}$ & $\begin{array}{l}1971 \\
1972\end{array}$ \\
\hline $\begin{array}{l}\text { Os sistemas ideais de } \\
\text { educação: primeira parte }\end{array}$ & $\begin{array}{l}\text { J. Roberto } \\
\text { Moreira }\end{array}$ & 1945 \\
\hline $\begin{array}{l}\text { Colégio Coração de } \\
\text { Jesus em Florianópolis - } \\
\text { SC }\end{array}$ & $\begin{array}{l}\text { Colégio } \\
\text { Sagrado } \\
\text { Coração de } \\
\text { Jesus }\end{array}$ & 1939 \\
\hline $\begin{array}{l}\text { Pétalas semestral do } \\
\text { Colégio Coração de } \\
\text { Jesus - Florianópolis - } \\
\text { SC }\end{array}$ & $\begin{array}{c}\text { Colégio } \\
\text { Sagrado } \\
\text { Coração de } \\
\text { Jesus }\end{array}$ & 1935 \\
\hline Primeiro Livro de Leitura & Série Fontes & 1945 \\
\hline $\begin{array}{l}\text { Problemas educacionais } \\
\text { de hygiene de Oswaldo }\end{array}$ & $\begin{array}{l}\text { Oswaldo } \\
\text { Rodrigues } \\
\text { Cabral }\end{array}$ & 1929 \\
\hline Quarto Livro de Leitura & Série Fontes & 1940 \\
\hline $\begin{array}{l}\text { Revista de Educação } \\
\text { (Ano 1, janeiro-fevereiro) }\end{array}$ & $\begin{array}{c}\text { Autor não } \\
\text { identificado }\end{array}$ & 1935 \\
\hline $\begin{array}{l}\text { Revista de Educação - } \\
\text { Revista Pedagógica (Ano } \\
\text { II - n. 7) }\end{array}$ & $\begin{array}{c}\text { Autor não } \\
\text { identificado }\end{array}$ & 1932 \\
\hline Segundo Livro de Leitura & Série Fontes & $\begin{array}{l}1920 \\
1941 \\
1945\end{array}$ \\
\hline Terceiro Livro de Leitura & Série Fontes & $\begin{array}{l}1939, \\
1943\end{array}$ \\
\hline $\begin{array}{l}\text { Vamos estudar? }-3^{\underline{a}} \text {. } \\
\text { Série primária }\end{array}$ & $\begin{array}{l}\text { Theobaldo } \\
\text { Miranda } \\
\text { Santos }\end{array}$ & 1965 \\
\hline
\end{tabular}

Fonte: Inventário do setor de Obras Raras (2012). Quadro elaborado pelas autoras.
Figura 05: Anais da 1ạ. Conferência Estadual do ensino primário (1927)

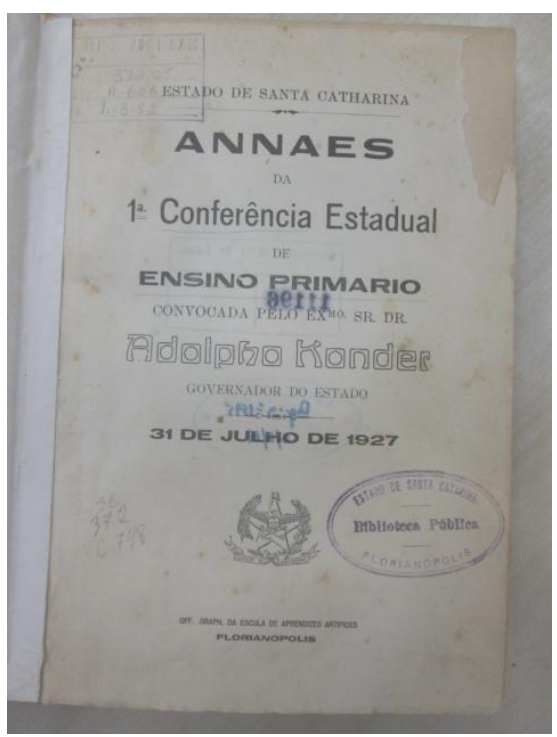

Fonte: Biblioteca Pública de Santa Catarina - Coleção Obras Raras de Santa Catarina. Imagem: Acervo pessoal das autoras.

No terceiro quadro destacamos obras relacionadas à educação, mas que não se caracterizam como legislação/livros e revistas/jornais. É o caso dos anais da Conferência Estadual do Ensino Primário ocorrida em Santa Catarina em 1927 (figura 05), que permite compreender um ideário pedagógico moderno para a escola primária a partir da retórica sobre temas educacionais escolhidos para serem tratados em eventos dessa ordem ${ }^{12}$. Além das atas, destacamos no quadro 3 discursos proferidos na ocasião de formaturas ou aniversários de escolas, pareceres/comentários sobre a instrução pública no estado e um documento sobre a Assistência a menores em Santa Catarina.

Obras diversas

${ }^{12}$ Sobre isso ver: HOELLER, 2014. 


\begin{tabular}{|c|c|}
\hline TÍTULO & DATA \\
\hline $\begin{array}{l}\text { A instrução pública em Santa Catarina } \\
\text { nos períodos de } 1750 \text { a } 1834\end{array}$ & 1948 \\
\hline $\begin{array}{l}\text { A organização actual do ensino no } \\
\text { Estado de Santa Catarina }\end{array}$ & $\mathrm{s} / \mathrm{d}$ \\
\hline $\begin{array}{l}\text { Annaes da } 1^{\text {a }} \text { conferência estadual de } \\
\text { ensino primário convocada pelo Exmo. } \\
\text { Sr. Dr. Adolpho Konder }\end{array}$ & 1927 \\
\hline $\begin{array}{l}\text { Assistência a menores em Santa } \\
\text { Catarina }\end{array}$ & 1943 \\
\hline $\begin{array}{l}\text { Comentários sobre a monografia A } \\
\text { educação em Santa Catarina, de Orlando } \\
\text { Ferreira de Melo }\end{array}$ & 1955 \\
\hline $\begin{array}{l}\text { Discurso do governador Jorge Lacerda } \\
\text { no cinqüentenário do Colégio } \\
\text { Catarinense }\end{array}$ & 1956 \\
\hline $\begin{array}{l}\text { Discurso pronunciado pelo Dr. Nereu } \\
\text { Ramos como paraninfo da primeira turma } \\
\text { de vocacionalistas do Instituto de } \\
\text { Educação de Florianópolis }\end{array}$ & 1938 \\
\hline $\begin{array}{l}\text { Falando às mestras - Antonieta de } \\
\text { Barros }\end{array}$ & 1946 \\
\hline $\begin{array}{l}\text { Grupo escolar "José Boiteux" e escola } \\
\text { normal primária (Discurso do paraninfo } \\
\text { da 1a. Turma de normalistas primárias, } \\
\text { pronunciado no salão do clube "Seis de } \\
\text { Janeiro", do Estreito) }\end{array}$ & 1939 \\
\hline $\begin{array}{l}\text { Nacionalização do ensino - aspectos } \\
\text { políticos }\end{array}$ & 1942 \\
\hline $\begin{array}{l}\text { Instituto de Educação de Florianópolis, } \\
\text { discurso de Nereu Ramos }\end{array}$ & 1938 \\
\hline $\begin{array}{l}\text { O ensino normal do } 1^{\circ} \text { ciclo - estudo para } \\
\text { uma reformulação }\end{array}$ & 1962 \\
\hline
\end{tabular}

Quadro 3: Obras diversas

Fonte: Inventário do setor de Obras Raras (2012). Quadro elaborado pelas autoras.

Jornais (Hemeroteca)

Atualmente, a seção mais estruturada do setor corresponde aos jornais catarinenses. O catálogo dos jornais, disponível no site da instituição, oferece alguns indícios sobre o volume de obras disponíveis:

Ao comemorar 160 anos de intensa atividade, a Biblioteca Pública de Santa Catarina (BPSC), instituição cultural vinculada administrativamente à Fundação Catarinense de Cultura, órgão da Secretaria de Estado de Turismo, Cultura e Esporte, faz chegar ao seu público a edição revista e ampliada do Catálogo de Jornais Catarinenses: 18312013. Dos 476 títulos dispostos no primeiro catálogo, publicado há 24 anos, a presente publicação eleva para 1.483 títulos de periódicos oriundos das mais variadas cidades que compõem o território catarinense [...]. (BPSC, 2013, p. 5)

A organização da seção é fruto do trabalho de profissionais da biblioteca e da parceria desta com a Fundação Biblioteca Nacional, que disponibilizou cópias de microfilmes contendo 327 títulos, muitos deles publicados no século XIX e início do século XX, ampliando assim 0 acervo catarinense. Outra importante parceria envolve a Associação de Jornais do Interior de Santa Catarina ADJORI/SC, que remete mensalmente à Biblioteca Pública as edições dos periódicos publicados nas cidades catarinenses, cumprindo assim os dispositivos da Lei $\mathrm{n} \cong 11.074$, de 11 de janeiro de 1999 (Lei do Depósito Legal de Obras Impressas).

A BPSC em parceria com o Centro de Ciências Humanas e da Educação (FAED), da Universidade do Estado de Santa Catarina (UDESC), e do Instituto de Documentação e Investigação em Ciências Humanas (IDCH), organizou a "Hemeroteca Digital

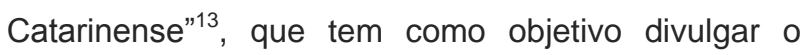
acervo documental de publicações periódicas, em especial jornais editados e publicados em Santa Catarina a partir do século XIX, promovendo o acesso a fontes documentais selecionadas, organizadas e estruturadas, em formato digital. Os exemplares impressos permanecem sob os cuidados da biblioteca, podendo ser manuseados pelos pesquisadores, caso haja necessidade de contato direto com a materialidade.

\footnotetext{
${ }^{13}$ http://hemeroteca.biblioteca.sc.gov.br/HEMO.htm
} 
Figura 06: Estante da Coleção do Jornal 0

\section{Estado}

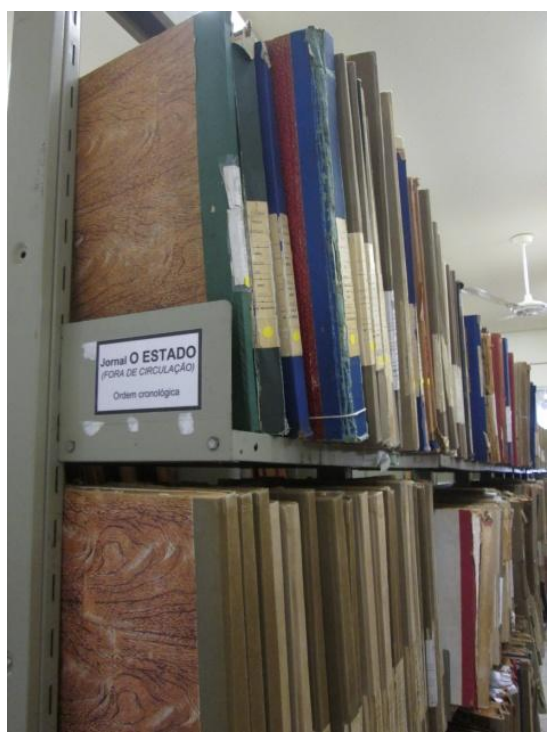

Fonte: Biblioteca Pública de Santa Catarina - Coleção Obras Raras de Santa Catarina. Imagem: Acervo pessoal das autoras.

Embora não trate de jornais "escolares", esse tipo de impresso oferece muitas indicações acerca da educação e da sociedade de maneira geral, como destacou Rosicler Schafascheck:

[...] o jornal é uma fonte privilegiada, um importante meio de expressão da visão de mundo de uma época, ao mesmo tempo em que colabora na produção e veiculação de determinada cultura. Além de apontar interesse e valores, os periódicos são produtores dos mesmos, à medida que disseminam ideias e procuram formar a opinião pública. (SCHAFASCHECK, 1997, pp. 8-9)

A pesquisa realizada por Schafascheck (1997), que mobiliza a relação entre educação/civilização e instrução/progresso a partir de artigos de jornais de Desterro (atual Florianópolis) da década de 1850, é representativa da utilização dos jornais como fonte de pesquisa em história da educação ${ }^{14}$.

\footnotetext{
${ }^{14}$ Como exemplo de estudo mobilizando jornais em interface com a educação, citamos a pesquisa que vem sendo desenvolvida por uma das autoras desse artigo, Hiassana Scaravelli, cujo objetivo principal é analisar o fortalecimento do comércio dos objetos escolares que acompanha a expansão do ensino da escola pública primária catarinense nos anos iniciais do século $X X$, tomando como referência anúncios de jornais. Título provisório da dissertação: "Dos jornais à escola: a comercialização de objetos em Santa Catarina (1908-1912)".
}

\section{Considerações finais}

Procuramos destacar, nesse artigo, alguns documentos presentes no setor de Obras Raras de Santa Catarina da BPSC, entendendo-os como parte do patrimônio educativo. A BPSC é um espaço que tem a preocupação de não apenas armazenar documentos, mas de preservar, conservar e disponibilizar à população um conjunto de obras relativas à "memória bibliográfica" do estado. A BPSC representa, nesse sentido, um lugar que evoca uma memória social, possibilitando diferentes leituras de fragmentos da história, inclusive da história da educação, que é, também, história social.

Além de indicar documentos salvaguardados na BPSC, entendida aqui como "lugar de memória", pretendemos contribuir para as discussões em torno da necessidade de políticas públicas que favoreçam a localização, o restauro, a organização e a guarda do patrimônio histórico-educativo.

\section{Referências}

BIBLIOTECA PÚBLICA DE SANTA CATARINA. Catálogo de jornais catarinenses: 1831-2013. Florianópolis: BPSC, 2014.

ESPÍNDOLA, Priscilla Lüdtke; DUARTE, Evandro Jair. Criação de uma proposta de critérios de seleção para as obras raras da Biblioteca Pública de Santa Catarina: relato de experiência. Revista $A C B$ : Biblioteconomia em Santa Catarina. Florianópolis, v. 19, n. 1, p. 135-146, jan./jun., 2014. Disponível em: < http://revista.acbsc.org.br/racb/article/view/944/pdf_94 >. Acesso em: 14 dez. 2015.

HOELLER, Solange Aparecida de Oliveira. As conferências educacionais: projetos para a nação e modernidade pedagógica nos anos de 1920 - Brasil. 2014. 480f. Tese (Doutorado) - Universidade Federal de Santa Catarina. Centro de Ciências da Educação, $2014 . \quad$ Disponível em: <https://repositorio.ufsc.br/xmlui/handle/123456789/1 29545>. Acesso em: 25 nov. 2015.

LE GOFF, Jacques. Documento/Monumento. In: História e Memória. Tradução Bernardo Leitão [et al]. Campinas, SP: Editora da Unicamp, 1990. p. 426-550.

Memória. In: História e Memória.

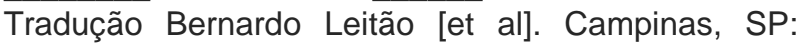
Editora da Unicamp, 1990. p. 366-418. 
MACHADO, César do Canto. Biblioteca Pública de Santa Catarina: 153 anos de história. Florianópolis: Insular, 2007.

NORA, Pierre. Entre memória e história: a problemática dos lugares. Projeto História, São Paulo, vol. 10, p. 7-28, dez., 1993

POSSAMAI, Zita Rosane. Patrimônio e História da Educação: aproximações e possibilidades de pesquisa. Revista História da Educação. V. 16, n. 36, p. 110-120, jan./abr., 2012. Disponível em: < http://seer.ufrgs.br/asphe/article/view/19976>. Acesso em: 10 out. 2015.

SANTA CATARINA. Lei no 11.074, de 11 de junho de 1999. Institui o Depósito Legal de Obras Impressas, junto à Biblioteca Pública do Estado de Santa Catarina. Florianópolis: ALESC, 1999 [?]. Disponível em:

$<$ http://200.192.66.20/alesc/docs/1999/11074_1999_L ei.doc>. Acesso em: 10 set. 2015.

Regulamento da Bibliotheca Publica do Estado de Santa Catharina. Florianópolis, 1894. Acervo: BPSC.

SCHAFASCHEK, Rosicler. Educar para civilizar e instruir para progredir: análise de artigos divulgados pelos Jornais do Desterro na década de 1850. 1997. 154f. Dissertação (Mestrado) - Universidade Federal de Santa Catarina, Centro de Ciências da Educação, $1997 . \quad$ Disponível em: <http://www.bu.ufsc.br/teses/PEED0169-D.pdf>. Acesso em: 24 set. 2015.

SCHENA, Valéria Ap. Livros de leitura da Série Fontes: ideias pedagógicas modernas no ensino primário de Santa Catarina. XIX Encontro Regional de História (ANPHU). Universidade Estadual do Paraná: Campo Mourão, 2014. Disponível em: < http://www.erh2014.pr.anpuh.org/anais/2014/395.pdf> . Acesso em: 10 dez. 2015.

STEINDEL, Gisela Eggert; TOLEDO, Luciane Gonçalves. A Biblioteca Pública de Santa Catarina como um lugar de práticas culturais - entre documentos e falas. Anais do Congresso Brasileiro de Biblioteconomia, Documentação e Ciência da Informação (CBBD). FEBAB, 2013. Disponível em: < http://portal.febab.org.br/anais/article/view/1270>.

Acesso em: 07 set. 2015.

SOUZA, Rosa Fátima de. Preservação do Patrimônio Histórico Escolar no Brasil: notas para um debate. Revista Linhas, Florianópolis, v. 14, n. 26, p. 199 221, jan./jun., 2013. Disponível em: <http://www.periodicos.udesc.br/index.php/linhas/artic le/view/1984723814262013199/2539>. Acesso em: 10 jul. 2015.

UNESCO. Manifesto da IFLA/UNESCO sobre bibliotecas públicas. IFLA/UNESCO, 1994. Disponível em: http://archive.ifla.org/VII/s8/unesco/port.htm. Acesso em: 15 set. 2015
VIDAL, Diana Gonçalves; FARIA FILHO, Luciano Mendes de. História da Educação no Brasil: a constituição histórica do campo e sua configuração atual. In: As lentes da história: estudos de história e historiografia da educação no Brasil. Campinas: Autores Associados, 2005. p. 73-127. 